\title{
Prevalence and antimicrobial susceptibility of Acinetobacter from raw bulk tank milk in Korea
}

\author{
M. Gurung, H. M. Nam, M. D. Tamang, M. H. Chae, G. C. Jang, S. C. Jung, and S. K. Lim ${ }^{1}$ \\ Bacterial Disease Division, Animal, Plant, and Fisheries Quarantine and Inspection Agency, Anyang-ro 157, Anyang, Gyeonggi-do, 430-757, \\ Republic of Korea
}

\begin{abstract}
The objective of this study was to determine the prevalence of Acinetobacter spp. in bulk tank milk (BTM) samples from different provinces of Korea and to analyze their antimicrobial susceptibility. Altogether, 2,287 BTM samples were investigated. Among them, Acinetobacter spp. were isolated from 176 BTM samples. Out of 176 Acinetobacter spp., 57 isolates were identified as Acinetobacter baumannii. None of the isolates were resistant to cefepime, imipenem, meropenem, ciprofloxacin, levofloxacin, or colistin. Resistance to amikacin, gentamicin, piperacillin, and cefotaxime was $2.3,7.4,2.3$, and $4.0 \%$, respectively. Acinetobacter spp. were least susceptible to tetracycline (17.6\%), followed by trimethoprim-sulfamethoxazole (15.9\%), ceftazidime (10.8\%), and ampicillin-sulbactam (10.2\%). Overall, A. baumannii strains were susceptible to most of the antimicrobial agents tested compared with other Acinetobacter spp. The Acinetobacter isolates showed 17 different patterns of antimicrobial resistance. The most frequent resistance profile observed was ampicillin-sulbactam $(\mathrm{n}=13)$, followed by tetracycline $(\mathrm{n}=$ $9)$, ceftazidime-tetracycline $(\mathrm{n}=8)$, and trimethoprimsulfamethoxazole-tetracycline $(\mathrm{n}=8)$. The results of this study confirmed that Acinetobacter, including $A$. baumannii strains, are present in BTM, which clearly showed the importance of examining BTM not only for foodborne pathogens but also for Acinetobacter spp., which could be of public health concern. To the best of our knowledge, this is the first report of Acinetobacter spp. in BTM samples from Korea.
\end{abstract}

Key words: Acinetobacter, antimicrobial resistance, bulk tank milk

\section{INTRODUCTION}

Milk and milk products are important sources of nutrients for both humans (Sharm and Joshi, 1992) and

Received July 20, 2012.

Accepted November 16, 2012.

${ }^{1}$ Corresponding author: imsk0049@korea.kr bacteria (Henry and Newlander, 1997). Therefore, it is mandatory to pasteurize milk for safety. Unfortunately, an increasing number of people consume raw (unpasteurized) milk and products made from raw milk despite the hazards associated with this practice. Consumption of raw milk has been associated with several milkborne disease outbreaks from 2000 to 2008 in the United States (Oliver et al., 2009). In contrast, fewer milkborne disease outbreaks were associated with consumption of pasteurized milk during this period (Oliver et al., 2009). These outbreaks were generally caused by improper pasteurization or postpasteurization contamination.

Bacterial isolates from bulk tank milk (BTM) consist of both pathogenic and commensal bacteria such as Staphylococcus aureus, Streptococcus agalactiae, Listeria monocytogenes, Enterococcus spp., Mycoplasma spp., Salmonella spp., Campylobacter jejuni, Escherichia coli, Enterobacter spp., Citrobacter spp., Klebsiella spp., and Yersinia enterocolitica (Jayarao and Wang, 1999; Jayarao and Henning, 2001; Straley et al., 2006). The study by Jayarao and Wang (1999) identified gram-negative noncoliform bacteria in BTM, including Acinetobacter, Aeromonas, Flavobacterium, Moraxella, Pasteurella, Pseudomonas, and Xanthobacter. A further worrying development is that antimicrobial resistant bacteria have been isolated from BTM, which is a matter of public health concern (Straley et al., 2006).

Acinetobacter species are aerobic, gram-negative, nonfermenting bacteria that are ubiquitous in nature (Bergogne-Bérézin and Towner, 1996). The organisms are characterized by their tendency to tolerate drying (Wendt et al., 1997; Webster et al., 1998), resist commonly used disinfectants such as chlorhexidine and phenols (Gallego and Towner, 2001$)$ and heat $\left(50-75^{\circ} \mathrm{C}\right.$; Jain and Danziger, 2004), adapt to adverse environmental conditions, and acquire resistance to multiple classes of antibiotics (Bergogne-Bérézin and Towner, 1996), facilitating the organism to survive and spread in the environment. Among them, Acinetobacter baumannii has emerged as an important pathogen, causing infections in severely ill patients in intensive care units or immunocompromised individuals (Bergogne-Bérézin 
and Towner, 1996; Villegas and Hartstein, 2003). Acinetobacter baumannii also resist the killing action of normal human serum, which was partly thought to be due to the presence of LPS (King et al., 2009).

To date, investigations of BTM are limited to established or potential pathogens of animals and humans. Furthermore, several reports exist on the prevalence of Acinetobacter from the environment and human clinical isolates, but only a very few studies have investigated the prevalence of Acinetobacter from BTM samples worldwide (Jayarao and Wang, 1999). Recently, our group reported the prevalence and antimicrobial susceptibility of gram-negative bacteria (GNB) from milk samples from Korea. However, these studies were limited to mastitic-quarter milk samples (Nam et al., 2009, 2010). Therefore, the present study was undertaken to investigate the prevalence of Acinetobacter in BTM samples and determine their antimicrobial susceptibility in Korea.

\section{MATERIALS AND METHODS}

\section{Bulk Tank Milk Sampling}

Bulk tank milk from 2,287 different dairy farms located in 6 provinces of Korea was collected during November 2011 to April 2012. The milk in the bulk tank was agitated for 5 to $10 \mathrm{~min}$ before sampling. Then, the sample was collected from the top of the tank in a sterile snap cap milk collection vial using a sterile dipper from each dairy farm. The BTM samples were brought to the antimicrobial resistance laboratory of the Animal, Plant, and Fisheries Quarantine and Inspection Agency (QIA, Gyeonggi-do, Republic of Korea) in ice-cooled containers and processed within $24 \mathrm{~h}$ of collection.

\section{Isolation of Acinetobacter}

Ten microliters of each milk sample was plated by streaking on CHROMagar Acinetobacter (CHROMagar, Paris, France) and incubated at $37^{\circ} \mathrm{C}$ for 48 h. The suspected red colonies of Acinetobacter were further subcultured on MacConkey agar and a single colony from MacConkey agar was further subcultured on Tryptic soy agar for DNA extraction and other experiments.

\section{Identification of Acinetobacter}

For identification of Acinetobacter spp., amplification and sequencing of the RNA polymerase $\beta$-subunit $(r p o \mathrm{~B})$ gene was done by using primers and the protocol as described previously (La Scola et al., 2006).
For rpoB-positive isolates, amplification of the 16S$23 \mathrm{~S}$ rRNA gene intergenic spacer region was done to identify the Acinetobacter calcoaceticus-A. baumannii complex as described previously (Barry et al., 1991). Finally, A. baumannii was differentiated from the $A$. calcoaceticus- $A$. baumannii complex by the DNA gyrase, subunit B ( gyrB)-based multiplex PCR method as described previously (Higgins et al., 2007).

\section{Antimicrobial Susceptibility Testing}

Antimicrobial susceptibility test of Acinetobacter was performed by the agar disc diffusion method according to the guidelines of the Clinical Laboratory Standards Institute (CLSI, 2010) using Mueller Hinton agar (Becton Dickinson, Sparks, MD). The antimicrobial drugs tested were amikacin (30 $\mu \mathrm{g} /$ disc), gentamicin $(10 \mu \mathrm{g} /$ disc $)$, ampicillin-sulbactam [10 $\mu \mathrm{g} /$ disc of each (ampicillin and sulbactam)], piperacillin $(100 \mu \mathrm{g} / \mathrm{disc})$, cefotaxime $(30 \mu \mathrm{g} /$ disc $)$, cefepime $(30 \mu \mathrm{g} /$ disc $)$, ceftazidime $(30 \mu \mathrm{g} /$ disc $)$, imipenem (10 $\mu \mathrm{g} /$ disc $)$, meropenem $(10 \mu \mathrm{g} /$ disc $)$, ciprofloxacin $(5 \mu \mathrm{g} /$ disc $)$, levofloxacin $(5$ $\mu \mathrm{g} /$ disc $)$, tetracycline $(30 \mu \mathrm{g} /$ disc $)$, colistin $(10 \mu \mathrm{g} /$ disc), and trimethoprim-sulfamethoxazole (1.25-23.75 $\mu \mathrm{g} /$ disc; Becton Dickinson, Cockeysville, MD). Isolates were categorized as susceptible or resistant based on interpretive criteria according to CLSI guidelines (CLSI, 2010). Escherichia coli ATCC 25922 and Pseudomonas aeruginosa ATCC 27853 were used as a quality control strains.

\section{RESULTS AND DISCUSSION}

In this study, 2,287 BTM samples were investigated. Among them, Acinetobacter spp. were isolated from 176 of $2,287(7.7 \%)$ of the BTM samples. Out of 176,57 isolates $(32.4 \%)$ were identified as A. baumannii. A study conducted by Jayarao and Wang, (1999) in eastern South Dakota and western Minnesota detected coliform and noncoliform bacteria in 62.3 and $76.3 \%$ of BTM samples, respectively. Although, they found several GNB in BTM samples, the isolation rate for Acinetobacter spp. was only $1.3 \%$. Acinetobacter spp. also have been reported from dairy goat milk samples in Kenya where the isolation rate was 5\% (Ndegwa et al., 2001). Similarly, our group investigated the prevalence and antimicrobial susceptibility of GNB from mastitic milk samples from Korea (Nam et al., 2009) in which the isolation rate of Acinetobacter spp. was 0.3\%. However, the isolation rates of Acinetobacter spp. in those studies were lower than that of the current study. The reason for this discrepancy is unclear. It is possible that there could be inhibition of Acinetobacter spp. from other bacteria or compounds in the mastitic milk that were 
absent in the current study, but it should be confirmed by further study. Nevertheless, the use of selective methods for the isolation of Acinetobacter spp. in BTM samples in the current study may, in part, explain the higher prevalence of Acinetobacter spp. as compared with those previous studies. Although our group previously reported the prevalence of Acinetobacter spp. from Korea from mastitic-quarter milk samples (Nam et al., 2009), to the best of our knowledge, this is the first report of prevalence of Acinetobacter spp. in BTM samples from Korea. Acinetobacter spp. were graded as the third most recurrently found pathogen in humans in intensive care units of hospitals in Korea (Kim et al., 2006). Furthermore, A. baumannii isolates were reported in pets and horses from Switzerland in which the majority of the infections were hospital acquired and in animals with predisposing conditions (Endimiani et al., 2011). This shows that Acinetobacter spp. were not only important nosocomial pathogens in humans, but also in animals.

Acinetobacter spp. are ubiquitous organisms that are widely distributed in nature. Thus, the presence of Acinetobacter in BTM could be due to mere contamination. Bulk tank milk can become contaminated with Acinetobacter present on teats, udder surfaces, infected mammary glands, milking machines, transporting systems, and contaminated water used to clean the milking machines, or from the dairy farm environment (Thomas and Thomas, 1973; Bramley and McKinnon, 1990; Straley et al., 2006). Although Acinetobacter spp. are virtually avirulent for healthy humans and cause infections almost exclusively in debilitated patients in hospitals and immunocompromised individuals (Bergogne-Bérézin and Towner, 1996; Villegas and Hartstein, 2003), antimicrobial resistant Acinetobacter spp. in BTM could be potential reservoirs of resistance genes, as they may survive pasteurization due to their ability to resist heat (Jain and Danziger, 2004). Furthermore, milk gets contaminated with a variety of microbes even after pasteurization (Brisabois et al., 1997; Oliver et al., 2005) and results in rapid multiplication of the microbes, which may change the quality of milk, leading to issues of food safety (Frazier and Westhoff, 1986). Thus, the presence of Acinetobacter resistant to multiple antibiotics in BTM is a matter of public health concern.

Acinetobacter spp. are intrinsically resistant to many antibiotics and possesses remarkable ability to acquire resistance determinants to various kinds of antimicrobial agents (Perilli et al., 1996). The antimicrobial susceptibility of $A$. baumannii $(\mathrm{n}=57)$ and other Acinetobacter spp. $(\mathrm{n}=119)$ to 14 antimicrobial agents is compared in Table 1. None of the other Acinetobacter spp. was resistant to cefepime, imipenem, meropenem, ciprofloxacin, levofloxacin, or colistin. The resistance to amikacin, gentamicin, piperacillin, and cefotaxime against Acinetobacter spp. was $2.3,7.4,2.3$, and $4.0 \%$, respectively. Overall, both A. baumannii and Acinetobacter spp. were least susceptible to tetracycline $(17.6 \%)$, followed by trimethoprim-sulfamethoxazole (15.9\%), ceftazidime (10.8\%), and ampicillin-sulbactam (10.2\%). Further, our results showed that carbapenem, fluoroquinolone, cefepime, and colistin were found to be the most active agents against all Acinetobacter including A. baumannii. Although no comparable data are available for Acinetobacter isolates from BTM samples worldwide, the resistance of human clinical Acinetobacter isolates from the United States for fluoroquinolone, amikacin, ceftazidime, and imipenem were very high (Lee et al., 2011). The clinical Acinetobacter isolates from humans from Korea also showed high resistance against fluoroquinolone, aminoglycosides, cephalosporin, and carbapenem (Lee et al., 2011). Compared with the human Acinetobacter isolates, the majority of Acinetobacter isolates from BTM samples in the current study were found to be susceptible to most of the antibiotics tested. This could be explained by the fact that the cattle from which they were isolated, being healthy cattle, were not exposed to antimicrobial agents.

Among the 57 A. baumannii isolates, none of the isolates were resistant to amikacin, piperacillin, cefotaxime, cefepime, ceftazidime, imipenem, meropenem, ciprofloxacin, levofloxacin, or colistin. Resistance to gentamicin, ampicillin-sulbactam, tetracycline, and trimethoprim-sulfamethoxazole in A. baumannii isolates was $8.8,1.8,7.0$, and $5.3 \%$, respectively. In contrast, Nam et al. (2010), reported much higher resistance for amikacin (5.9\%), piperacillin (5.9\%), and tetracycline (18\%) among the $17 \mathrm{~A}$. baumannii isolated from mastitic-quarter milk samples in Korea. The higher resistance in that study may be attributed to selective pressure caused by the use of these antimicrobial agents for treatment of mastitis in the infected cattle. Similarly, human clinical A. baumannii isolates from Korean hospitals also exhibited a high frequency of resistance to various classes of antimicrobial agents, including aminoglycosides, extended-spectrum $\beta$-lactams, fluoroquinolone, and carbapenem (Lee and Moon, 2005). As described above, nonexposure to antimicrobial agents may be the reason for low level resistance of A. baumannii isolates in the current study compared with human isolates.

In the present study, the most frequently observed antimicrobial resistance in Acinetobacter isolates was to tetracycline $(17.6 \%)$, which is similar to findings in E. coli isolates from cattle and pigs in Korea (Lim et al., 2007). This result reflects the use of antimicrobial agents in livestock in Korea, as tetracycline has long 
Table 1. Antimicrobial susceptibility of Acinetobacter spp. isolated from raw bulk tank milk in Korea

\begin{tabular}{|c|c|c|c|c|c|}
\hline Class & Antimicrobial & $\begin{array}{l}\text { Breakpoint } \\
\text { zone }(\mathrm{mm})\end{array}$ & \multicolumn{3}{|c|}{ No. of resistant isolates $(\%)^{1}$} \\
\hline Aminoglycosides & Gentamicin & $\overline{\leq} 12$ & $8(6.7)$ & $5(8.8)$ & $13(7.4)$ \\
\hline \multirow[t]{2}{*}{ Penicillins } & Ampicillin-sulbactam & $\leq 11$ & $17(14.3)$ & $1(1.8)$ & $18(10.2)$ \\
\hline & Piperacillin & $<17$ & $4(3.4)$ & $0(0)$ & $4(2.3)$ \\
\hline \multirow[t]{2}{*}{ Carbapenems } & Imipenem & $\leq 13$ & $0(0)$ & $0(0)$ & $0(0)$ \\
\hline & Meropenem & $\overline{\leq} 13$ & $0(0)$ & $0(0)$ & $0(0)$ \\
\hline \multirow[t]{2}{*}{ Fluoroquinolones } & Ciprofloxacin & $\leq 15$ & $0(0)$ & $0(0)$ & $0(0)$ \\
\hline & Levofloxacin & $\overline{\leq} 13$ & $0(0)$ & $0(0)$ & $0(0)$ \\
\hline Tetracyclines & Tetracycline & $\leq 11$ & $27(22.7)$ & $4(7.0)$ & $31(17.6)$ \\
\hline Polymyxins & Colistin & $\overline{<} 11$ & $0(0)$ & $0(0)$ & $0(0)$ \\
\hline
\end{tabular}

${ }^{1}$ The numbers in parentheses indicate percentages of resistant isolates.

been the antimicrobial most commonly used with Koran livestock, accounting for over $30 \%$ of the total amount of antimicrobial consumption (Animal, Plant, and Fisheries Quarantine and Inspection Agency, 2011). As tetracycline resistance genes such as tet(39) have been found associated with horizontally transferable plasmids (Agers $\varnothing$ and Guardabassi, 2005; Agers $\varnothing$ and Petersen, 2007), these plasmids may spread among Acinetobacter spp. in dairy farms. Furthermore, resistance to tetracycline in Acinetobacter is also mediated by overexpression of chromosomally encoded efflux pumps (Coyne et al., 2011).
Overall, Acinetobacter isolates showed 17 different patterns of antimicrobial resistance in this study. The most frequent resistance profile observed was to ampicillin-sulbactam-trimethoprim-sulfamethoxazole $(\mathrm{n}=13)$, followed by tetracycline $(\mathrm{n}=9)$, ceftazidimetetracycline $(\mathrm{n}=8)$, and trimethoprim-sulfamethoxazole-tetracycline $(\mathrm{n}=8)$. Altogether, 33 isolates showed resistance to at least 1 antimicrobial agent tested, whereas 42 and 3 isolates showed simultaneous resistance to 2 and 3 antimicrobial agents, respectively. The resistance profiles of these isolates are shown in Table 2. Multidrug-resistant (MDR) Acinetobacter

Table 2. Antimicrobial resistance profiles of Acinetobacter spp. isolated from raw bulk tank milk in Korea

\begin{tabular}{|c|c|c|c|c|}
\hline \multirow[b]{2}{*}{$\begin{array}{l}\text { No. of resistant } \\
\text { antimicrobials }\end{array}$} & \multirow[b]{2}{*}{$\begin{array}{l}\text { Resistance } \\
\text { pattern }^{1}\end{array}$} & \multicolumn{3}{|c|}{ No. of resistant isolates $(\%)^{2}$} \\
\hline & & $\begin{array}{l}\text { Acinetobacter spp. } \\
\quad(\mathrm{n}=119)\end{array}$ & $\begin{array}{c}\text { Acinetobacter } \\
\text { baumannii }(\mathrm{n}=57)\end{array}$ & $\begin{array}{c}\text { Total } \\
(\mathrm{n}=176)\end{array}$ \\
\hline $0(\mathrm{n}=98)$ & - & $50(42.0)$ & $48(84.2)$ & $98(55.7)$ \\
\hline \multirow{7}{*}{$1(\mathrm{n}=33)$} & AMK & $4(3.4)$ & $0(0)$ & $4(2.3)$ \\
\hline & AMS & $4(3.4)$ & $0(0)$ & $4(2.3)$ \\
\hline & CAZ & $3(2.5)$ & $0(0)$ & $3(1.7)$ \\
\hline & GEN & $3(2.5)$ & 2 & $5(2.8)$ \\
\hline & PIP & $5(4.2)$ & $0(0)$ & $5(2.8)$ \\
\hline & SXT & $2(1.7)$ & $1(1.8)$ & $3(1.7)$ \\
\hline & TET & $7(5.9)$ & $2(3.5)$ & $9(5.1)$ \\
\hline \multirow[t]{7}{*}{$2(\mathrm{n}=42)$} & AMS-SXT & $12(10.0)$ & $1(1.8)$ & $13(7.4)$ \\
\hline & CAZ-CTX & $6(5.0)$ & $0(0)$ & $6(3.4)$ \\
\hline & CAZ-GEN & $1(0.8)$ & $0(0)$ & $1(0.6)$ \\
\hline & CAZ- TET & $8(6.7)$ & $0(0)$ & $8(4.5)$ \\
\hline & GEN-TET & $2(1.7)$ & $1(1.8)$ & $3(1.7)$ \\
\hline & SXT-GEN & $2(1.7)$ & $1(1.8)$ & $3(1.7)$ \\
\hline & SXT-TET & $8(6.7)$ & $0(0)$ & $8(4.5)$ \\
\hline \multirow[t]{3}{*}{$3(\mathrm{n}=3)$} & AMS-SXT-TET & $1(0.8)$ & $0(0)$ & $1(0.6)$ \\
\hline & CAZ-CTX-TET & $1(0.8)$ & $0(0)$ & $1(0.6)$ \\
\hline & SXT-GEN-TET & $0(0)$ & $1(1.8)$ & $1(0.6)$ \\
\hline
\end{tabular}


strains have emerged as a substantial clinical problem worldwide (Lee et al., 2011). Different definitions of the terms MDR and pandrug-resistant A. baumannii have been used in the literature. In this study, MDR Acinetobacter spp. were defined as the isolates resistant to at least 3 different classes of antimicrobial agents (Magiorakos et al., 2012). By this definition, only 2 MDR Acinetobacter strains were detected in this work. In contrast, several outbreaks of MDR Acinetobacter spp., particularly MDR A. baumannii have been reported worldwide, including Korea (Lee et al., 2011).

\section{CONCLUSIONS}

We determined the prevalence of Acinetobacter spp. in BTM samples from different provinces of Korea and analyzed their antimicrobial susceptibility. Acinetobacter isolates were detected in a relatively high number of BTM samples, which clearly showed the importance of examining BTM not only for foodborne pathogens but also for Acinetobacter spp., as this could also be a potential problem associated with milk quality as well as public health.

\section{ACKNOWLEDGMENTS}

This work was supported by a grant from the Animal, Plant, and Fisheries Quarantine and Inspection Agency, Ministry of Food, Agriculture, Forestry and Fisheries (Gyeonggi-do, Republic of Korea).

\section{REFERENCES}

Agersø, Y., and L. Guardabassi. 2005. Identification of Tet 39, a novel class of tetracycline resistance determinant in Acinetobacter spp. of environmental and clinical origin. J. Antimicrob. Chemother. 55:566-569.

Agers $\varnothing$, Y., and A. Petersen. 2007. The tetracycline resistance determinant Tet 39 and the sulphonamide resistance gene sulII are common among resistant Acinetobacter spp. isolated from integrated fish farms in Thailand. J. Antimicrob. Chemother. 59:23-27.

Animal, Plant, and Fisheries Quarantine and Inspection Agency. 2011. Establishment of antimicrobial resistance surveillance for livestock. Animal, Plant, and Fisheries Quarantine and Inspection Agency, Anyang, South Korea.

Barry, T., G. Colleran, M. Glennon, L. K. Dunican, and F. Gannon. 1991. The $16 \mathrm{~S} / 23 \mathrm{~S}$ ribosomal spacer region as a target for DNA probes to identify eubacteria. PCR Methods Appl. 1:51-56.

Bergogne-Bérézin, E., and K. J. Towner. 1996. Acinetobacter spp. nosocomial pathogens: Microbiological, clinical, and epidemiological features. Clin. Microbiol. Rev. 9:148-165.

Bramley, A. J., and C. H. McKinnon. 1990. The microbiology of raw milk. Pages 163-208 in Dairy Microbiology. Vol. 1. 2nd ed. R. K. Robinson, ed. Elsevier Appl. Sci., New York, NY.

Brisabois, A., V. Lafarge, A. Brouillaud, M. L. de Buyser, C. Collette, B. Garin-Bastuji, and M. F. Thorel. 1997. Pathogenic organisms in milk and milk products: The situation in France and in Europe. Rev. Sci. Tech. 16:452-471.

CLSI (Clinical and Laboratory Standards Institute). 2010. Performance standards for antimicrobial susceptibility testing; 20th informational supplement. M100-S20-U. CLSI, Wayne, PA.
Coyne, S., P. Courvalin, and B. Périchon. 2011. Efflux-mediated antibiotic resistance in Acinetobacter spp. Antimicrob. Agents Chemother. 55:947-953.

Endimiani, A., K. M. Hujer, A. M. Hujer, I. Bertschy, A. Rossano, C. Koch, V. Gerber, T. Francey, R. A. Bonomo, and V. Perreten. 2011. Acinetobacter baumannii isolates from pets and horses in Switzerland: Molecular characterization and clinical data. J. Antimicrob. Chemother. 66:2248-2254.

Frazier, W. C., and D. C. Westhoff. 1986. Foodborne infections and intoxications: Bacterial. Pages 521-540 in Food Microbiology. TMH ed. Cambridge University Press, Cambridge, MA.

Gallego, L., and K. J. Towner. 2001. Carriage of class 1 integrons and antibiotic resistance in clinical isolates of Acinetobacter baumannii from northern Spain. J. Med. Microbiol. 50:71-77.

Henry, A., and I. Newlander. 1997. Milk Constituents. Pages 269-273 in Chemistry and Testing of Dairy Products. 5th ed. John Wiley and Sons Inc., New York, NY.

Higgins, P. G., H. Wisplinghoff, O. Krut, and H. Seifert. 2007. A PCRbased method to differentiate between Acinetobacter baumannii and Acinetobacter genomic species 13TU. Clin. Microbiol. Infect. 13:1199-1201.

Jain, R., and L. H. Danziger. 2004. Multidrug-resistant Acinetobacter infections: An emerging challenge to clinicians. Ann. Pharmacother. 38:1449-1459.

Jayarao, B. M., and D. R. Henning. 2001. Prevalence of foodborne pathogens in bulk tank milk. J. Dairy Sci. 84:2157-2162.

Jayarao, B. M., and L. Wang. 1999. A study on the prevalence of gramnegative bacteria in bulk-tank milk. J. Dairy Sci. 82:2620-2624.

Kim, K. M., J. H. Yoo, J. H. Choi, E. S. Park, K. S. Kim, K. S. Kim, S. R. Kim, S. M. Kim, H. J. Kim, J. S. Jung, K. H. Yoo, H. S. Oh, S. W. Yoon, M. R. Suh, Y. K. Yoon, J. Y. Lee, Y. S. Jang, H. Y. Jin, S. W. Kim, Y. R. Kim, Y. S. Kim, Y. S. Kim, J. U. Kim, J. M. Kim, K. R. Peck, H. Lee, M. D. Oh, S. H. Oh, W. K. Lee, S. H. Lee, M. H. Chung, S. I. Jung, H. J. Cheong, and W. S. Shin. 2006. The nationwide surveillance results of nosocomial infections along with antimicrobial resistance in intensive care units of sixteen university hospitals in Korea, 2004. Korean J. Nosocomial Infect. Control 11:79-86.

King, L. B., E. Swiatlo, A. Swiatlo, and L. S. McDaniel. 2009. Serum resistance and biofilm formation in clinical isolates of Acinetobacter baumannii. FEMS Immunol. Med. Microbiol. 55:414-421.

La Scola, B., V. A. K. B. Gundi, A. Khamis, and D. Raoult. 2006. Sequencing of the rpoB gene and flanking spacers for molecular identification of Acinetobacter species. J. Clin. Microbiol. 44:827-832.

Lee, K., D. Yong, S. H. Jeong, and Y. Chong. 2011. Multidrug-resistant Acinetobacter spp.: Increasingly problematic nosocomial pathogens. Yonsei Med. J. 52:879-891.

Lee, M. A., and H. W. Moon. 2005. In vitro activity of antimicrobial combination against multidrug-resistant strains of Acinetobacter baumannii. Korean J. Lab. Med. 25:312-316.

Lim, S. K., H. S. Lee, H. M. Nam, Y. S. Cho, J. M. Kim, S. W. Song, Y. H. Park, and S. C. Jung. 2007. Antimicrobial resistance observed in Escherichia coli strains isolated from fecal samples of cattle and pigs in Korea during 2003-2004. Int. J. Food Microbiol. 116:283-286.

Magiorakos, A.-P., A. Srinivasan, R. B. Carey, Y. Carmeli, M. E. Falagas, C. G. Giske, S. Harbarth, J. F. Hindler, G. Kahlmeter, B. Olsson-Liljequist, D. L. Paterson, L. B. Rice, J. Stelling, M. J. Struelens, A. Vatopoulos, J. T. Weber, and D. L. Monnet. 2012. Multidrug-resistant, extensively drug-resistant and pandrug-resistant bacteria: An international expert proposal for interim standard definitions for acquired resistance. Clin. Microbiol. Infect. $18: 268-281$.

Nam, H. M., S. K. Lim, H. M. Kang, J. M. Kim, J. S. Moon, K. C. Jang, J. M. Kim, Y. S. Joo, and S. C. Jung. 2009. Prevalence and antimicrobial susceptibility of gram-negative bacteria isolated from bovine mastitis between 2003 and 2008 in Korea. J. Dairy Sci. 92:2020-2026.

Nam, H.-M., S.-K. Lim, J.-M. Kim, Y.-S. Joo, K.-C. Jang, and S.-C. Jung. 2010. In vitro activities of antimicrobials against six im- 
portant species of gram-negative bacteria isolated from raw milk samples in Korea. Foodborne Pathog. Dis. 7:221-224.

Ndegwa, E. N., C. M. Mulei, and S. J. Munyua. 2001. Prevalence of microorganisms associated with udder infections in dairy goats on small-scale farms in Kenya. J. S. Afr. Vet. Assoc. 72:97-98.

Oliver, S. P., K. J. Boor, S. C. Murphy, and S. E. Murinda. 2009. Food safety hazards associated with consumption of raw milk. Foodborne Pathog. Dis. 6:793-806.

Oliver, S. P., B. M. Jayarao, and R. A. Almeida. 2005. Foodborne pathogens in milk and dairy farm environment: Food safety and public health environment. Foodborne Pathog. Dis. 2:115-129.

Perilli, M., A. Felici, A. Oratore, G. Cornaglia, G. Bonfiglio, G. M. Rossolini, and G. Amicosante. 1996. Characterization of the chromosomal cephalosporinases produced by Acinetobacter lwoffii and Acinetobacter baumannii clinical isolates. Antimicrob. Agents Chemother. 40:715-719.

Sharm, D. K., and D. V. Joshi. 1992. Bacteriological quality of milk and milk product with special reference to Salmonella and its health significance. J. Sci. Technol. 22:100-103.
Straley, B. A., S. C. Donaldson, N. V. Hedge, A. A. Sawant, V. Srinivasan, S. P. Oliver, and B. M. Jayarao. 2006. Public health significance of antimicrobial-resistant gram-negative bacteria in raw bulk tank milk. Foodborne Pathog. Dis. 3:222-233.

Thomas, S. B., and B. F. Thomas. 1973. Psychrotrophic bacteria in refrigerated bulk-collected milk. Part I. Dairy Indus. 38:11-15.

Villegas, M. V., and A. I. Hartstein. 2003. Acinetobacter outbreaks, 1977-2000. Infect. Control Hosp. Epidemiol. 24:284-295.

Webster, C. A., M. Crowe, H. Humphreys, and K. J. Towner. 1998. Surveillance of an adult intensive care unit for long-term persistence of a multi-resistant strain of Acinetobacter baumannii. Eur. J. Clin. Microbiol. Infect. Dis. 17:171-176.

Wendt, C., B. Dietze, E. Dietz, and H. Rüden. 1997. Survival of Acinetobacter baumannii on dry surfaces. J. Clin. Microbiol. 35:1394-1397. 